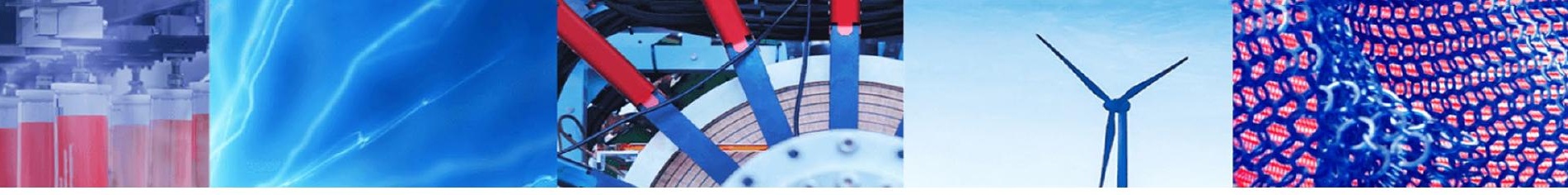

Research Article

\title{
Particle colliders market development and evolution models
}

\author{
Alexey Zabolotsky ${ }^{1}$ (D) \\ Received: 5 August 2019 / Accepted: 3 February 2020 / Published online: 15 February 2020 \\ (c) Springer Nature Switzerland AG 2020
}

\begin{abstract}
Main goal of this article-assessment of scientific projects and their economic impact. This assessment includes economic and technological feasibility on the example of elementary physics collider projects. Methodology includes structural integration in other technological fields by means of self-organizing neural maps and anthological retrospective analysis of radical discoveries with their recent impetus for economic development. Self-organizing neural map helps to expose hidden structural similarities of technology spreading and integration with other technologies. This is a new approach exposing the capacity for technology convergence into other industries. Capacity evaluations for integration and emergence of new technologies on the frontiers of elementary particles physics is provided. Explanation of integration problems in explained. Novelty of the study is based on integration of physical attributes into economics enabling new explanations of technology development models. Risk adjusted net present value evaluation is carried out. Comparison of similar projects around the world created in the article shows common frames and model of collider projects development. Risk adjusted model takes into account integration potential of technology under study. Conclusion combining obtained results in neural maps and historical retrospection is made.
\end{abstract}

Keywords Self-organized neural map · Project evaluation · Economic impact · Collider project · Elementary particle physics

JEL Classification $\mathrm{L} 60 \cdot \mathrm{L} 6 \cdot \mathrm{C} 45 \cdot \mathrm{C} 52$

\section{Introduction}

It is proposed to implement evaluation of collider complexes prospects for elementary particles physics and collider industry in particular case and economics in general. There are two projects in the field or particle physics launched in Russian Federation within the frames of mega Science program-NICA (Moscow) and Tau Fabric (Novosibirsk). This projects are targeted at elaboration of fundamental background in Elementary Particles Physics discipline by means of new approaches-shifting from particles energy to their luminosity to obtain greater results in new discoveries and possible economic applications. These new approaches propose model of discovering new phenomena and particles with increasingly higher level of luminosity occurring while particles collide at different angles. According to recently created theories such luminosity influence number of emerging particles and events in collider detectors. But Tau Fabric projects raised several urgent issues about it's economic and technological viability. There are several works, evaluating collider projects with technological cost models [1] and economic evaluation methods, but they do not take into account critical points and negative outcomes [2] introducing virtual benefits and intangible assets and income by means of manipulating with market class borders uncertainty [3].

Alexey Zabolotsky, ieie@inbox.ru| ${ }^{1}$ Institute of Economics and Industrial Engineering, Lavrentyeva 17, 373, Novosibirsk, Russian Federation 630090. 
Aside from critical point this work implements selforganized neural map models to analyze integration of collider technologies into other industries. Self organized neural map models have found their applications in almost all scientific and technological disciplines like biotechnology, microelectronics, engineering, chemistry since 1980's and has been implemented there and have successfully substituted conventional PCA and other methods. Though in economics this method started emerging quite recently. Self-organizing maps have serious advantages in structural dependencies and similarities unveiling between complex objects [4], that makes them popular in many scientific disciplines [5].

\section{Methodology}

\subsection{Structural integration of elementary particle physics in economics at meso-level}

In this work info metrics system of technological structural self organization in 24 industries based on patent activity indicators in Russian regions is proposed. According to the main thesis self organization can be a signature of new innovations emergence and growth [6]. But, several assumptions should be made. Basic drawback of such models is distance or similarity between info metric objects that are in this case technological. So angle separation formula applied for measuring similarity [7] is taking into account angular relations or distance between classes of multidimensional objects generated on the base of proper vectors.

$S_{i j}=\frac{\sum_{k=1}^{n} x_{i j} \times x_{j k}}{\sum_{k=1}^{n} x_{i k}^{2} \times \sum_{y=1}^{n} x_{j y}^{2}}$

This formula is derived from Euclidean metric system and looks like this:

$\cos \alpha=\frac{a_{1} \times b_{1}+\cdots+a_{n} \times b_{n}}{\sqrt{a_{1}^{2}+\cdots+a_{n}^{2}} \times \sqrt{b_{1}^{2}+\cdots+b_{n}^{2}}}$

For common Euclidean space this formulas are correct but when applied to econometric data they distort real objects substitute composition of this objects with false complexity. They create distorted dependency model and thus can violate rules of space dimensions creation. For example technological vector $T$ consisting of sub vectors $\left(x_{1}, \ldots, x_{n}\right)$ representing dimensions composed from patent class data for particular technology in reality consist of single "patent" dimension. Most of authors omit this issue and implement angular separation methods for class or object separation and measuring distance [7].

$\Omega_{u v}^{E A}=\frac{\sum_{e=1}^{T} J_{u t} J_{u t}}{\sqrt{\sum_{e=1}^{T} J_{u t}^{2} \sum_{e=1}^{T} J_{v t}^{2}}}$

Numerous measures like this are based on angular separation between classes or [7-9] or adjacent class juxtaposition and measures of their overlapping [10-12] or probability distance measures [13] based on hypergeometric distribution of probability. As Jaffe states [9] if there is fundamental measure-it is possible to create proper space and measure in it. But this statement also contains obstacles because measure in technological space can be made between classes only. But patent classes have only one dimension-number of patents, and according to the rules of measuring distance between such groups only distance in one-dimensional space between centroids of such classes is viable. But in this case structural complexity of object is lost. Attempt to create real fundamental parameter for each class like biotechnology or electronics in technological space will be based on technological parameters - mass, size, logical structure, complexity and so on. And this approach will shift study outside economic discipline. In this case compromise variant should be Euclidean measures to expose technological patterns for each objects studied and Decart coordinates to create compatible system for object mapping.

Aside from mentioned problems with multidimensionality there are problems with heteroscedasticity, nonlinearity of data dependencies, their collinearity and non Haussian distribution patterns. This creates obstacles while finding dependency paths between influencing and dependent factors. Well known Kendal or Person correlation coefficients surmise pairwise object dependencies and reactions occurring after certain periods of time and within discrete geometric ranges for particular sets of data. But in real Nature or Economic systems such interactions are very rare and look like this in reality:

$\sum_{i, j}^{n, m} f(x, y) \leftrightarrow \sum_{j, i}^{m, n} f(x, y)$

Signature $\leftrightarrow$ means any pairwise all-angle directed and complex [14] between all elements $x$ and $y$ of set $f$. Thet means that formulas like (3) and all other coefficients are totally incompatible with this case (4). From the point of view of vector space actions can fill all the space and 


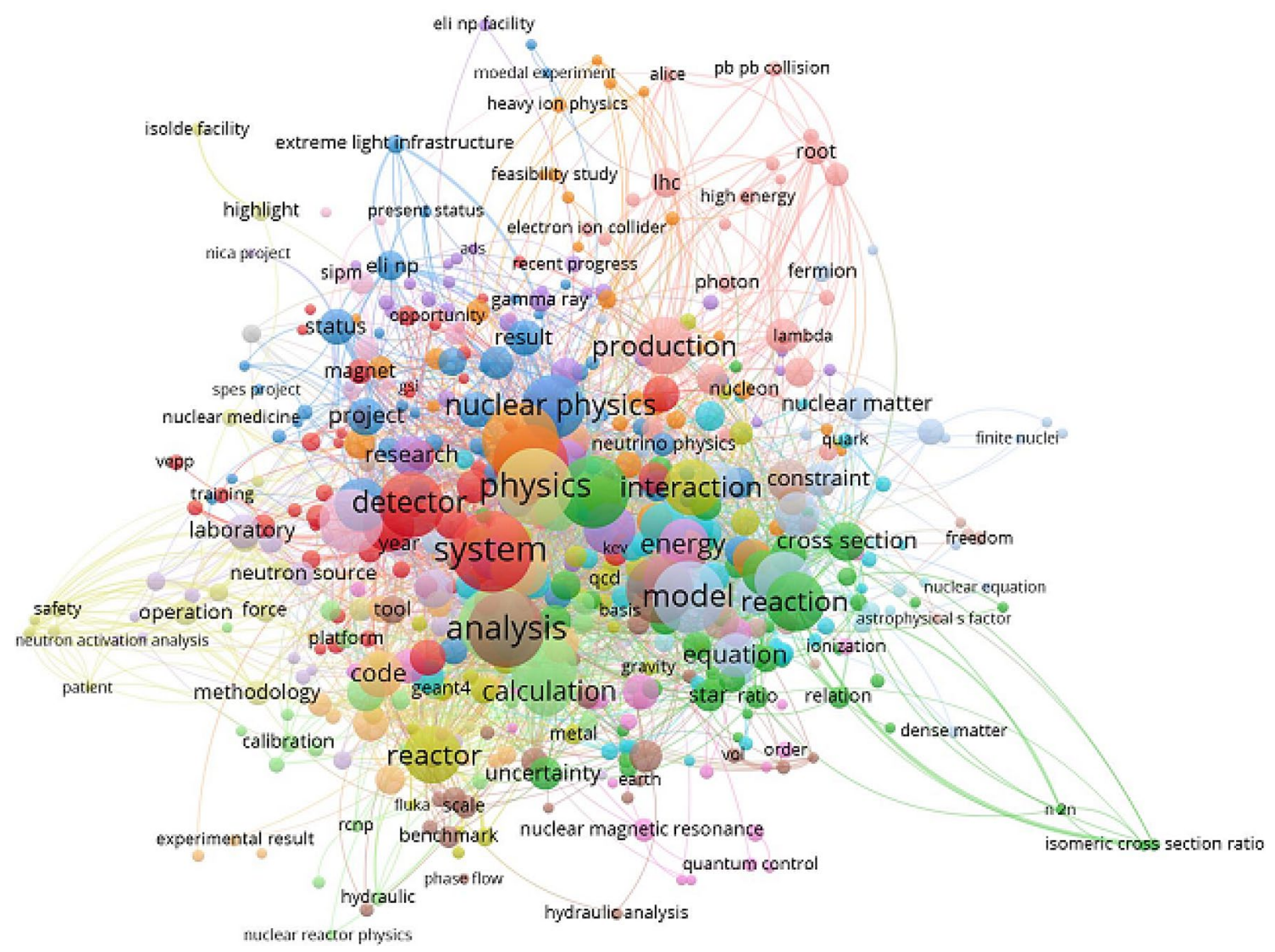

Fig. 1 Citation distribution in web of science of elementary particle physics discipline. Authors data

interaction variations but not only pairwise single directed interactions between similar rows of data.

All this drawbacks impose serious limitations for further data usage. This limitations are necessity of data verification for normality, heteroscedasticity, multicollinearity, outliners test and more complicated tests to find complex polymorphic of encapsulated dependencies. That's why it is proposed to apply self organized map to avoid this issues and to test proposed idea of technological self organization existence between technologies.

In order to build general picture of elementary physics discipline WOS reference data was taken from a collection of article citation map generated in graph software (WOS Viewer). Following map reflects strength and number of citations between disciplines of elementary particle physics and mostly adjacent to its other disciplines.

As it is evident from the picture most significant areas of applications which elementary particle physics connected with are theoretical ones. At the same time semiconductor discipline is integrated in applied areas of science despite of theoretical background prevalence.
As it can be seem from Figs. 1 and 2 elementary particles physics differs by significant inclination to theoretical disciplines like neutrino physics and fermions, methods and models while semiconductors juxtaposed with such areas as materials, equipment, circuits, devices, materials properties.

In order to create more precise and valid integration model patent data base in 24 technological directions across 80 regions of Russian Federation was created. Patents analysis has proven itself as highly valid and precise method [9]. Patent data was normalized as each technology has it's own dimensional distortions that influence overall model according to this or that technological peculiarities.

\subsection{Colliders comparison}

Before the analysis of Super Tau project it would be better to carry out anthology of radical innovations in Elementary Particle Physics or nuclear Physics in it's common meaning. Impact on economic growth is provided in the table also with data arranged according to timelines. 


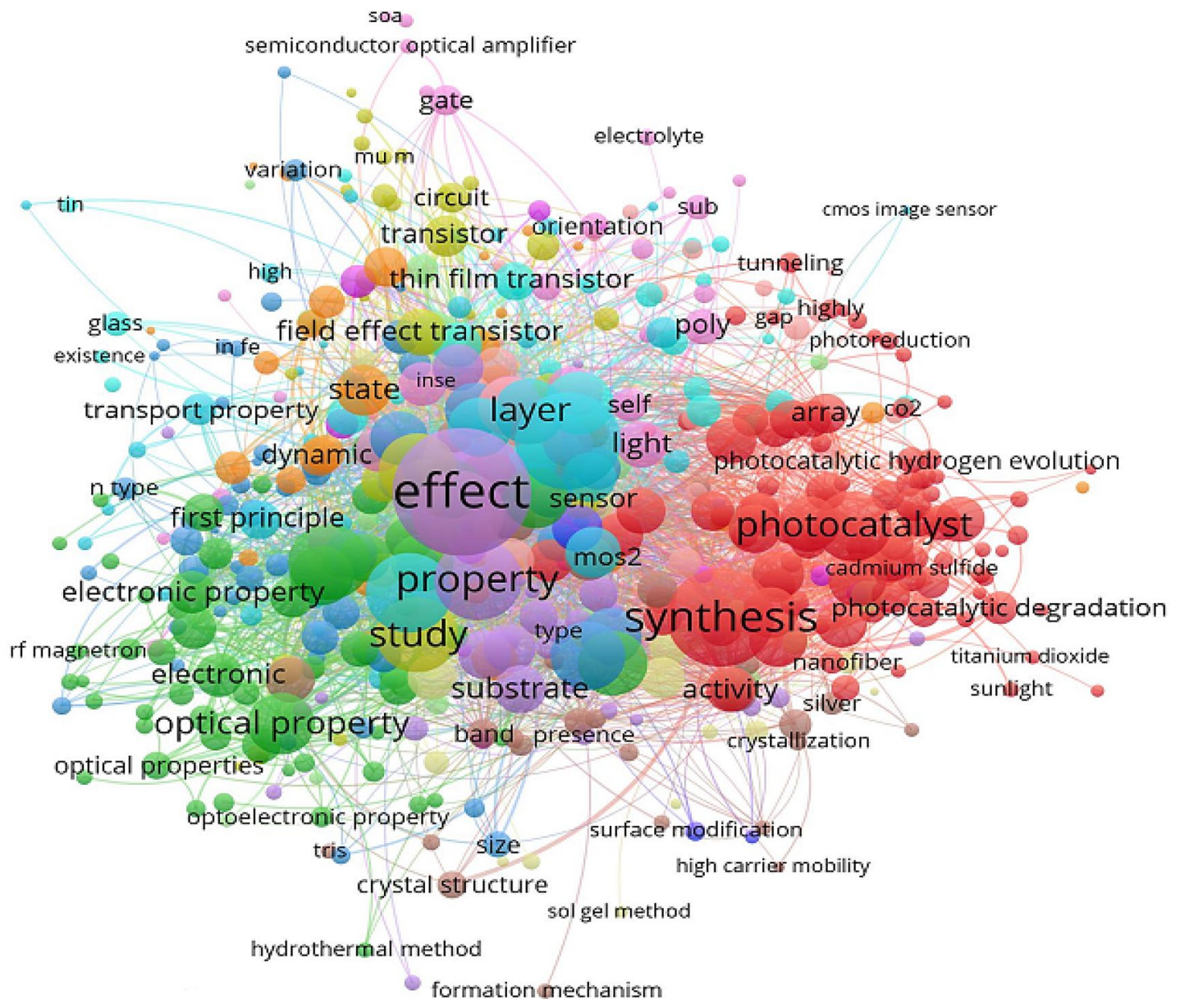

Fig. 2 Citation distribution in web of science of semiconductors discipline. Authors data

As it is evident from the table radical innovations economic impact went to zero since 1919. It was caused by divergence of physical parameters of discovered particles from economic, industrial and technological integration components parameters and properties [3], creating technological gap with economic systems [15]. Two key elementary physics parameters-energy [16] and life time predisposed emergence of this technological fracture between elementary particle physics with economic systems.

Table higher demonstrates comparison main colliders across the world with Tau Fabric. Economic effects and applications with key parameters and discoveries are shown. If we consider integration and applications common patterns can be noticed they are medicine therapy and diagnostics, food processing, isotope and new elements synthesis, irradiation. The closest one to Super Tau Charm Fabric is KEK collider in Japan that became famous for SP super symmetry violation discovery. There are other projects that became generators of dozens of new periodic elements. But all the new ones trans-fermium elements synthesized in recent decades have extremely short life time and produced in nano-scale volume. These factors caused obstacles for mentioned discoveries being integrated to other technologies (Table 1).

As it is seen from the Table 3 colliders are weakly integrated in most significant technological markets despite collider market is included on $100 \%$ in mentioned classes. ${ }^{1}$ Table down shows co-occurrence of technological direction with each other. Table shows patents co-occurrences of colliders with main patent classes. Such analysis could reveal integration capacity of each technology to form other technologies (Table 2).

As it is evident from the table, colliders show greater integration capacity with technologically compatible industries and technologies. This integration can lead to convergence with laser technologies [17], electronics and particle physics. But while comparing it to other technologies colliders show very low level of patent overlapping

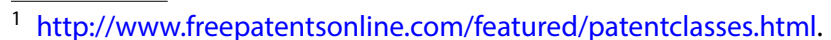


Table 1 Main markets and their integration

\begin{tabular}{llll}
\hline $\begin{array}{l}\text { Technological directions (aggre- } \\
\text { gation of patent classes) }\end{array}$ & GDP & Particles energy $^{\mathrm{a}}$ & Colliders \\
\hline Medicine & 305 billion USD $^{\mathrm{b}}$ & $0.1-1 \mathrm{eV}$ & 5.116 billion USD \\
Biotechnology & 440 billion USD $^{\mathrm{c}}$ & $0.1-0.4 \mathrm{eV}$ & 0 \\
Semiconductors & 412 billion USD $^{\mathrm{d}}$ & $1 \mathrm{meV}$ & 0 \\
Photonics & 636 billion USD $^{\mathrm{e}}$ & $1-4 \mathrm{eV}$ & 0 \\
Chemistry & 5700 billion USD & $0.2-20 \mathrm{eV}$ & 1 billion USD \\
Aviation and space & 190 billion USD & $1 \mathrm{eV}$ & 0 \\
Shipbuilding & 274 billion USD & $1 \mathrm{eV}$ & 0 \\
Electronics & 1172 billion USD & $1 \mathrm{eV}$. & 1 billion USD \\
Nanotechnology & 64.2 billion USD & $1 \mathrm{eV}$ & 0
\end{tabular}

${ }^{a}$ http://accelconf.web.cern.ch/accelconf/ipac2013/talks/weib201_talk.pdf

${ }^{b}$ https://www.grandviewresearch.com/industry-analysis/home-healthcare-industry

chttps://www.gminsights.com/industry-analysis/biotechnology-market

${ }^{d}$ https://asia.nikkei.com/Business/Business-trends/Global-semiconductor-market-to-shrink-12-in-2019trade-group

ehttps://www.mordorintelligence.com/industry-reports/photonics-market-market

${ }^{f}$ https://www.icca-chem.org/wp-content/uploads/2019/03/ICCA_EconomicAnalysis_Report_03081 9.pdf

${ }^{\mathrm{g}}$ https://www.prnewswire.com/news-releases/the-global-commercial-aircraft-market-valued-at-justover-us191-billion-in-2018-300703315.html

${ }^{\mathrm{h}}$ https://es.ndu.edu/Portals/75/Documents/industry-study/reports/2015/es-is-report-shipbuildi ng-2015.pdf

'https://www.globenewswire.com/news-release/2018/06/29/1531798/0/en/Global-Consumer-Elect ronics-Market-Will-Reach-USD-1-787-Billion-by-2024-Zion-Market-Research.html

jhttps://accelconf.web.cern.ch/accelconf/IPAC2013/papers/weib201.pdf

khttps://www.asminternational.org/c/portal/pdf/download?articleld=25986127\&groupld=10192 revealing integration capacity. Even though shipbuilding is the only technology with lower frequency of overlapping it is self-reliant technology that is characterized by low number of heavy components with high value added.

But there is significant other application as in already mention fields like high energy lasers. As scientists from Berkeley showed in their experiments lasers are perfect accelerators for electron-positron pairs with energies up to $44 \mathrm{GeV}$ [18] accelerating them with photon-photon and photon-electron interaction [19].

Elementary particle physics is high risk discipline not only as low profit technology but as a generator of a new fundamental results. It happens because nuclear physic per particle energy range and other parameters are much bigger than average among other disciplines. All other technologies integrated with each other because of material and process energy ranges round similar values of $1 \mathrm{eV}$ while particles building all the goods manufactured have unlimited life. Other technological direction have more similar patterns like similar functional behavior-transportation, communication, computation, food preparation and on while colliders main function is colliding particles and observing their result- - that stands apart from most technologies.

Elementary particle physics left the zone of economic indicators and that made it hard task to integrate nuclear physics in other sector of economics.

Recently some attempts to find alternatives for colliders are implemented. Some of them are ambitious or even unproven one's in military sector like creation of anti-nuclear neutrino weapon activating as it is expected nuclear warhead remotely or neutrino sources for detection of warheads [20,21]. Projects in biotechnology grasp such knowledge field as application of Vavilov-Cherenkov radiation for the development of biological processes monitoring within living cells in real time [22]. Economically beneficial technology seems to be chemical process study in real time by means of x-ray propagation induced with particle collisions or deceleration [22]. Beneficial directions can be predictive chemistry, molecules detection and catalytic process tracing in real time with high energy gamma rays, quantum phenomena studying and some other phenomena hardly processed with conventional methods. 


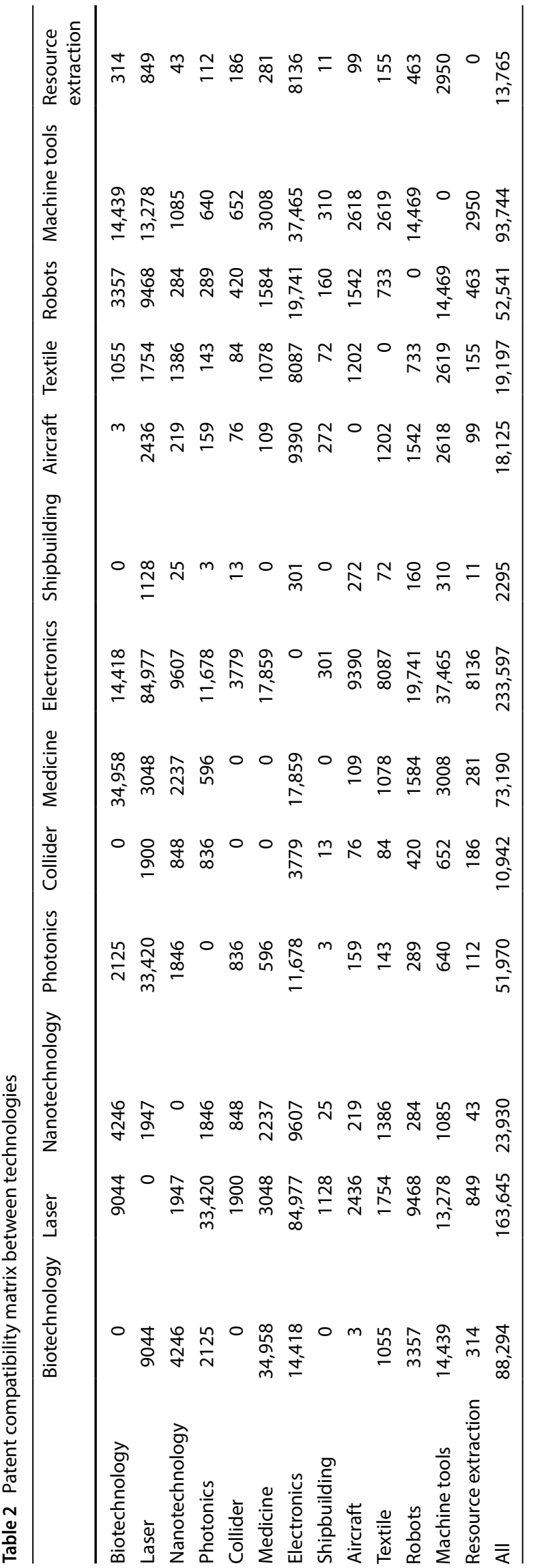

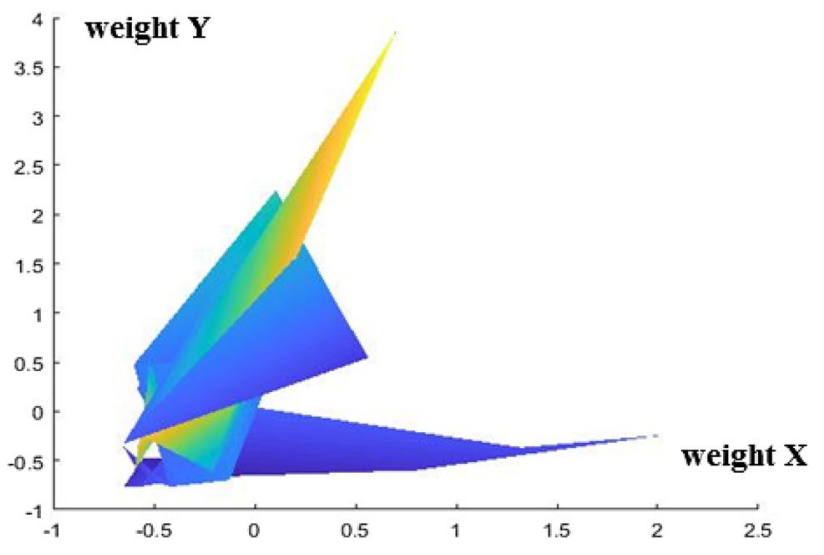

Fig. 3 Neuron weights distribution for 24 technologies in 80 regions of Russian Federation. Matlab Toolbox

Most stable technologies successfully implementing colliders and nuclear physics are pasteurization technologies implementing irradiation to protect food and medical equipment. Besides there are some assumptions that irradiation can be dangerous due to unpredictable chemical reactions massively induced by $10 \mathrm{MeV}$ electron beams.

Already mentioned method to implement neutrino as military project seems to prosperous as several research studies provided by [21] proved theoretical possibility to deploy neutrino sources at 1-200 Tev as military weapon or at least warhead detector. While other scientists proved that neutrino rays [23] lead to drastic increase of isotope decay [24] process thus giving some opportunity for implementation of mentioned technology. But general deceleration of radical innovation in elementary particle Physics can be a sign that even those neutrino ambitious plans will stay just a theory.

\section{Results}

\subsection{Self-organized neural model}

Figures down represent neural map weight distribution and heat maps, reflecting similarity or correlation patterns between fields of technology. Figures 3 and 5 reflect weight distribution of analyzed data while Figs. 4 and 6 correspond to the Euclidean metric distance similarities between objects in relevant space of dimensions.

Figure 3 higher reflects neurons distribution in Self organized neural map model created with Matlab SelfOrganized Map Toolbox. Asymmetric structure reveals poor distribution and imperfect self-organization, however it showed quite good level of precision with several patterns of similarity between input vectors corresponding to technologies (Fig. 4). 

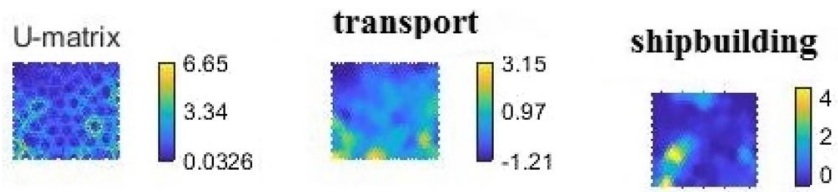

turbine

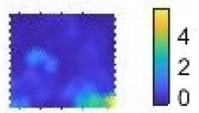

polymer

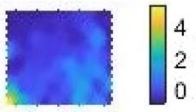

medicine

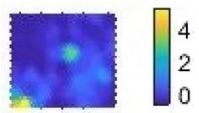

lithography

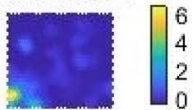

chemistry

engine
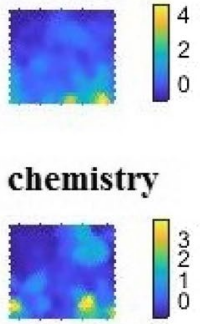

energetics

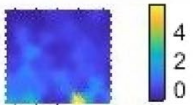

nanotechnology

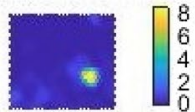

\section{petrochemistry}

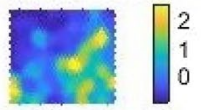

cattle breeding

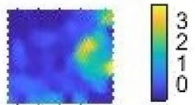

integrated circuit

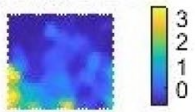

aviation

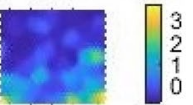

alloy

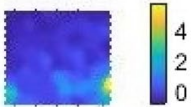

clothes

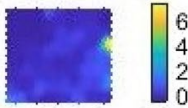

agriculture

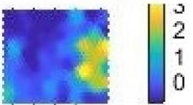

microelectronics

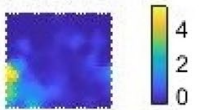

machine building

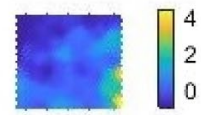

semiconductor

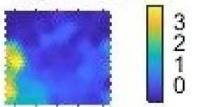

medical equipment

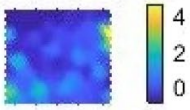

genetics

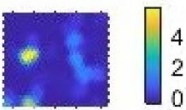

particle collider

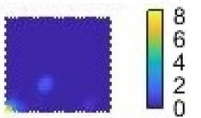

Fig. 4 Input vectors for 24 technologies

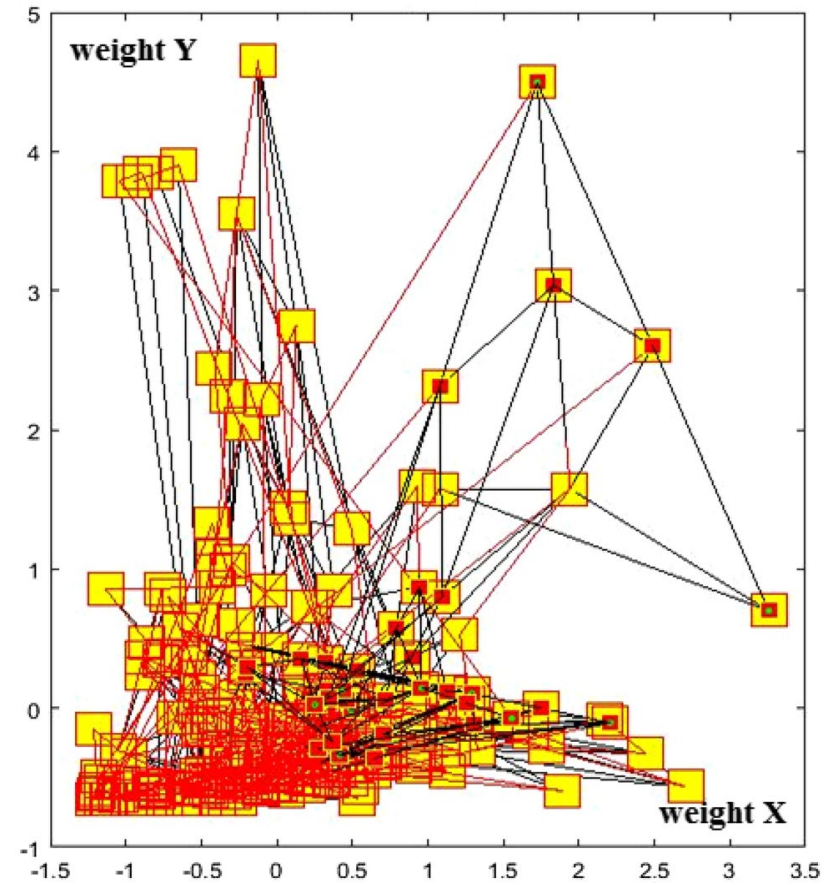

Fig. 5 Distribution of weight neurons in Matlab clustering tool
Figure higher demonstrates structural cross industrial dependencies in Matlab Toolbox. There are patterns of significance between aviation and turbines, machine tools and machine building, semiconductors and integrated circuits, integrated circuits and microelectronics.

But, at the same time there are no connection between each of 3 technologies integrated circuits, microelectronics, semiconductors and lithography equipment. That reveals lack of connections in this manufacturing chain or lacks necessary technological level and inner demand between technological chain elements within Russian Federation. Similar isolation can be seen for Elementary Particle Physics (Fig. 4).

Figure higher (Fig. 5) shows distribution of neurons weights for Matlab clustering tool (625 neurons corresponding to 24 input vectors). Despite lower precision of this package in comparison to Matlab Toolbox, distribution is more smooth and heteroscedastic with all neurons selforganized relatively to each other that is reflected in larger number of similar technological patterns between technologies as on the figure down. Closer structural similarities are reflected in closer topologies, while color reflects strength of connection with red as strongest connection yellow-weaker connection and black shows no connection with neural map [25] (Fig. 6). 

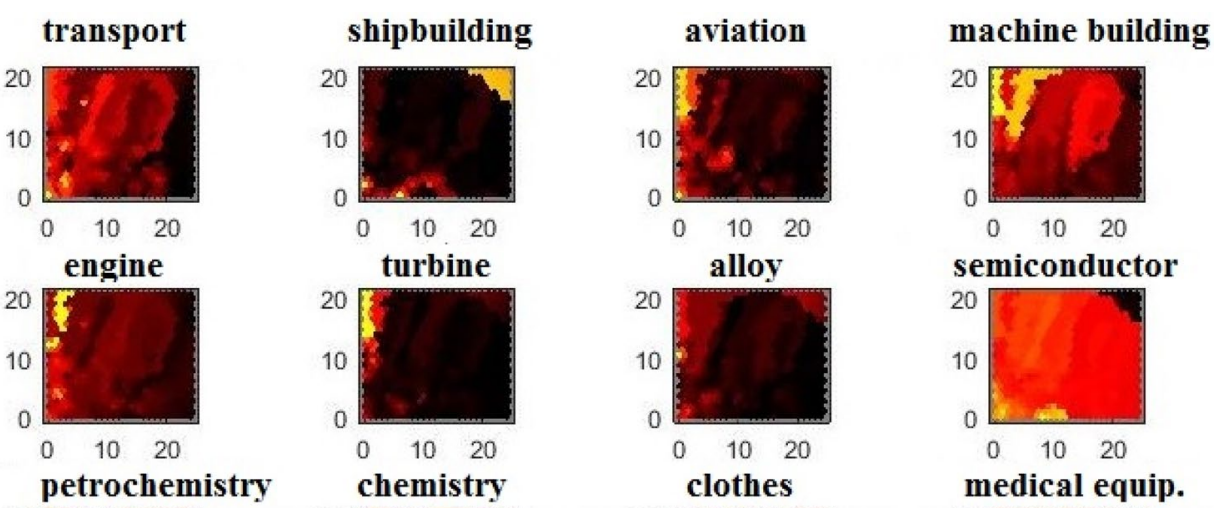

machine tools
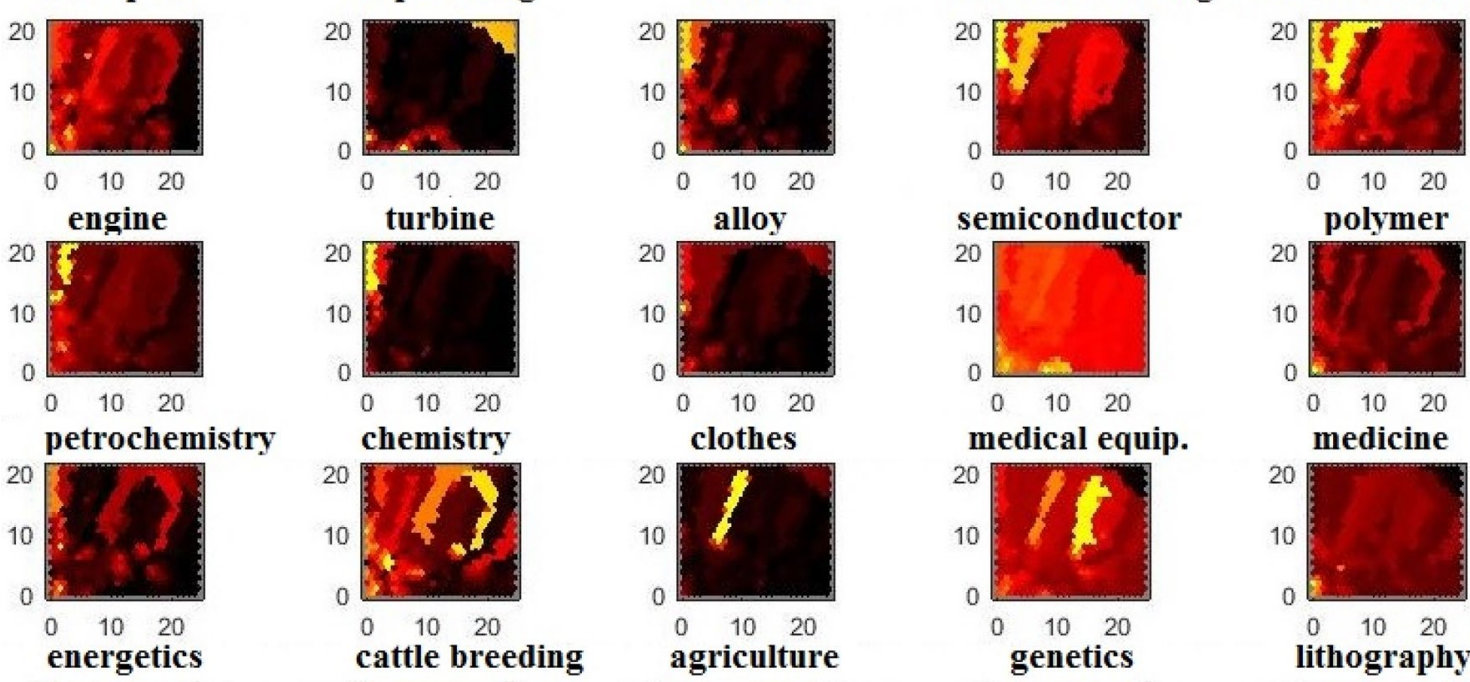

clothes
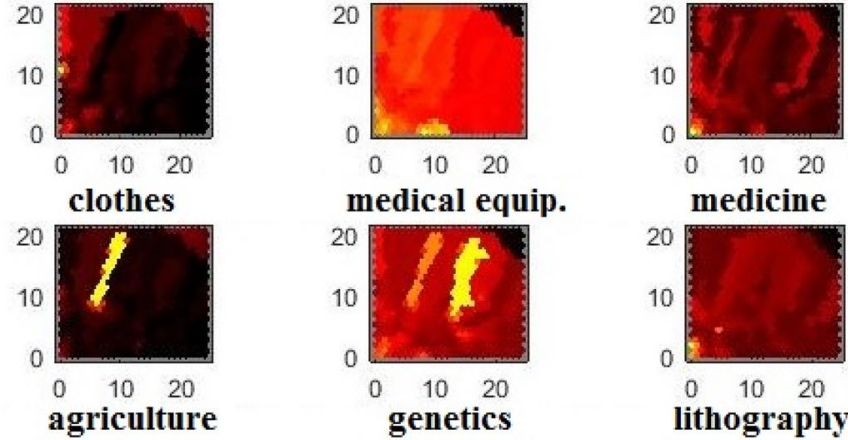

medicine
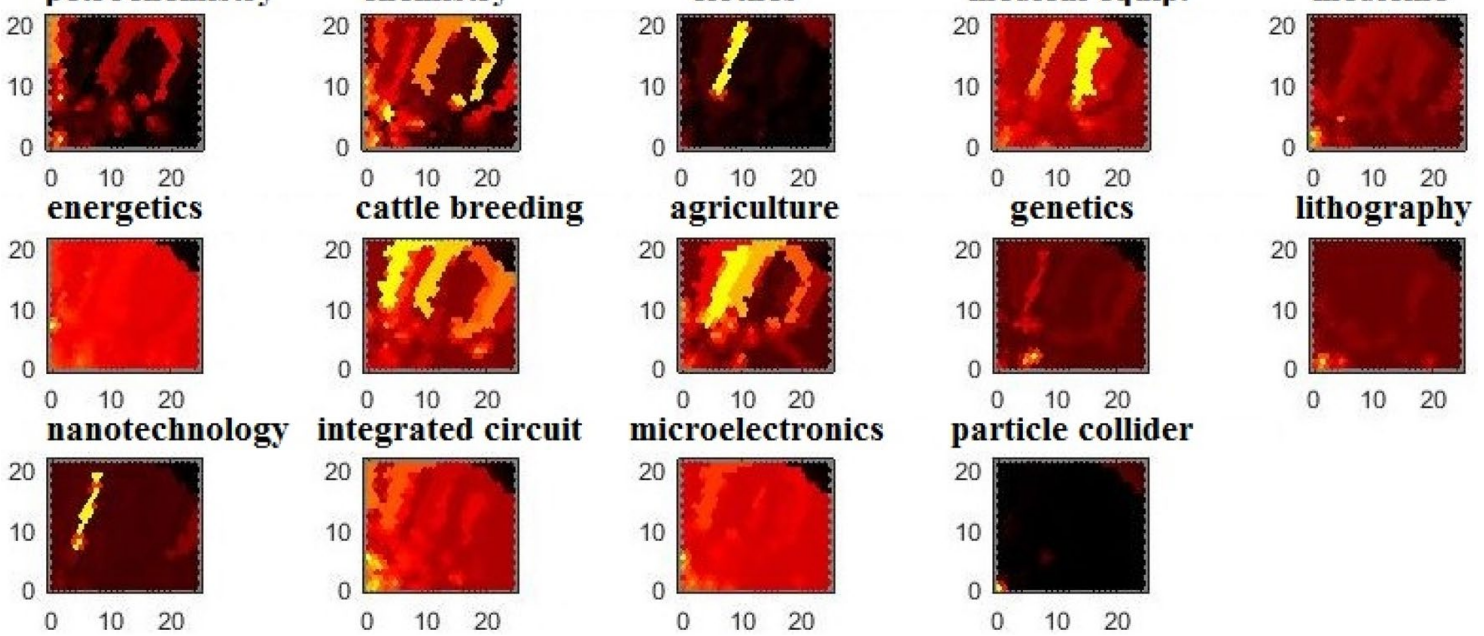

Fig. 6 Matlab clustering tool input vectors

Matlab clustering tool found more connections. They are machine and machine tools, turbines and aviation, chemistry and petro chemistry, integrated circuits and microelectronics, semiconductors and integrated circuits (very weak), genetics and nanotechnology (very weak), cattle breeding and agriculture. But colliders as major representative of elementary particle physics showed no similarities with other technologies even in this figure.

In this sense neural map creates "relative" similarities between input planes corresponding to input vectors.

\subsection{Project evaluation}

The only elementary Particles Technology that has applied implementation is particle colliders. There is a plenty of cost models developed for their estimation that are to be considered here.

Besides there are several types of collider project evaluations [26]. There is estimation based on key technological parameters [1]. But more recent estimation was made with the complex rNPV model taking into account aside indirect effects of collider. Model was created for CERN collider complex [2].
$T P C=\alpha\left(\frac{L}{10 \mathrm{~km}}\right)^{1 / 2}+\beta\left(\frac{E}{1 \mathrm{Tev}}\right)^{1 / 2}+\gamma\left(\frac{P}{100 \mathrm{MW}}\right)^{1 / 2}$

here $\mathrm{L}$-collider tunnel length, $\mathrm{E}$ - energy per 1 electron volt/centimeter, $P$ power. Coefficients $a, \gamma$ are economic parameters, a $\beta$ coefficient measured for technology. With $\pm 30 \%$ fluctuation $\alpha \beta \gamma$-model corresponds to actual collider costs in the Table 2 with coefficients $c a=\gamma=2$ billion. USD and coefficient $\beta$ equal to 1 billion.USD for NC magnets, 2 billion USD for SC magnets, 8 billion USD for NC RF and 10 billion USD for SC RF. ${ }^{2}$

Super Tau Fabric costs $=2$ billion.USD $* 0.089+2$ billion. USD $* 0.07+2$ billion. USD $* 0.8944=0.178+0.14+1.7888=2$ .1068 billion.USD. So Russian project Super Tau Charm Fabric is significantly cheaper, especially taking into account the fact that 40 billion rubles (650 million USD_rate 2019 June) will be spent on all the equipment and infrastructure with collider. And even with regard to purchasing power parity comparison that is still cheaper nearly $40 \%$ as GDP per capita in USA and Russian federation has ratio 2.19: 1 or $(65,112$ USD ppp) to $(29,642$ USD ppp).

\footnotetext{
${ }^{2}$ NC, SC, SC RF solenoid magnet types and technology.
} 
From the point of long term prospects CERN project from Switzerlandattract attention in many research studies with economic ones among them [27]. This studies provided standt evaluation models. Proposed model for LHC collider includes standard-Bti и Cti parameters that are benefits and costs in period t.R-discount rate at certain period $t_{i}$.

$N P V=\frac{B_{t_{i}}-C_{t_{i}}}{(1+R)^{t_{i}}}$

In order to quantize parameters for CERN model environmental approach [28] was adopted from [29], ${ }^{3}$ splitting NPV into parts: real income $N P V_{u}$ and unused income from expected and unused benefits EXV. $N P V_{u}$ is split into 4 parts of benefits and 4 variable of costs.

First part benefits consist of following variables scientific research articles based on CERN discoveries and their corresponding values, technological advantages for collaborating firms, human capital and cultural effect $\left(S C_{t_{i}}+T E_{t_{i}}+H C_{t_{i}}+C U_{t_{i}}\right)$. These variables are "Pro fit from publications" -280 million euro, like induced long term effects [27], "outer favorable factors" $T E_{t_{i}}-5.4$ billion euro, "Human Capital" $H C_{t_{i}}-5.5$ billion euro, "cultural effects" $C U_{t_{i}}$ -2.1 billion euro. Outer favorable factors can be effects on collider market sales or applications of nuclear physics in other areas. Cultural effects-payed services provided by CERN, research subcontracting, grants, funding. Expenditures include capital costs, scientists salary and S\&T expenditures, working personnel, operational costs $C_{t_{i}}=\left(K_{t_{i}}+L S_{t_{i}}+L O_{t_{i}}+O_{t_{i}}\right)=13.5$ bln.euro.

Variable EXVO describe unused projects prosperous capacity. General model looks following:

$$
\begin{aligned}
N P V= & \sum_{i}^{t} \frac{\left(S C_{t_{i}}+T E_{t_{i}}+H C_{t_{i}}+C U_{t_{i}}\right)-\left(K_{t_{i}}+L S_{t_{i}}+L O_{t_{i}}+O_{t_{i}}\right)}{(1+r)^{t}} \\
& +E X V 0 ;
\end{aligned}
$$

It is quite evident that authors wanted to promote project and installed virtual benefits because of well-known problem of fundamental science weak links to economic sectors. It is evident that authors exaggerated benefits. And this impose limits on application of such models in real project evaluations.

Real benefits can be created by application of adjacent collider markets. Its benefits can be composed of real sector applications and relevant services. There are areas of application in petro-chemistry, automobile industry. Aside from that there is a dozen of positron and electron colliders technologies deployed in diagnostics, medicine, testing, process monitoring. But these are mostly small

\footnotetext{
3 Pearce et al. [29].
}

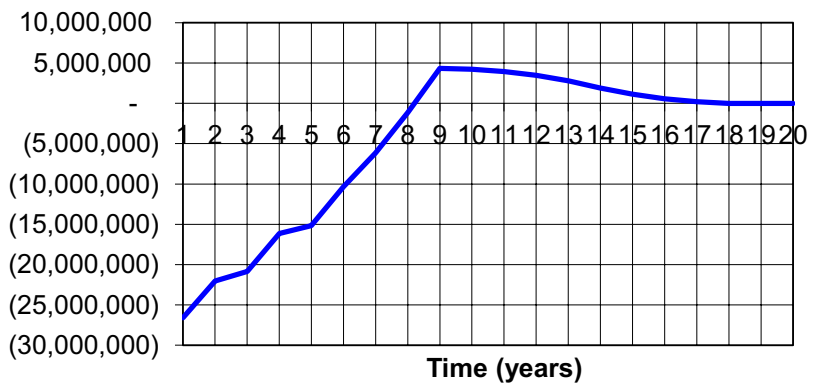

Fig. 7 RNPV model evaluation for Tau Fabric

specialized segment having competitor technologies in areas of medicine, chemistry, biotechnology, physics they are applied to. In proposed risk adjusted model rNPV size of market was adjusted according to neural model which excludes alternative market applications on contrast to other research [3] (Fig. 7).

Model obtained following results.

PV of revenue $=74,055,528$ usd.

$\mathrm{NPV}=-33,657,178$ usd.

$\mathrm{rNPV}=-26,584,021$ usd.

rTC $=739,225,062$ usd.

Overall Value of project $74,055,528$ dollars but with cost variables it is negative due to the high maintain costs and small market segments. rTC—risk adjusted total cost is equal to Tau Fabric price $r \mathrm{rC}=46,571,178,906$ roubles while project cost is 40 billion roubles roughly.

\section{Discussion}

As it was mentioned main disadvantage of Elementary Particle Physics is a big gap between it and other economic system that's why it is very hard to find possible alternative combinations of collider technologies aside from those very specialized. Though some prosperous applications were found while changing basic methods of research in this area. For example Nuclear Magnetic Resonance, that made revolution in diagnostics was discovered apparently from mainstream nuclear physics though it belongs to this research area.

Similar application became positron beam diagnostics implementing annihilation as diagnostic process in real time. Though some studies [30] report that even small doze of gamma rays can result in a heavy damage of cell and DNA structure [31]. Similar hesitation on the safety of products processed with ion beam particles occur in the food irradiation applications. Main idea of irradiation safety was based on relativistic approach that electronatom collisions can not lead to nuclei radiation emergence due to formation of new isotopes. But $10 \mathrm{MeV}$ electron can 


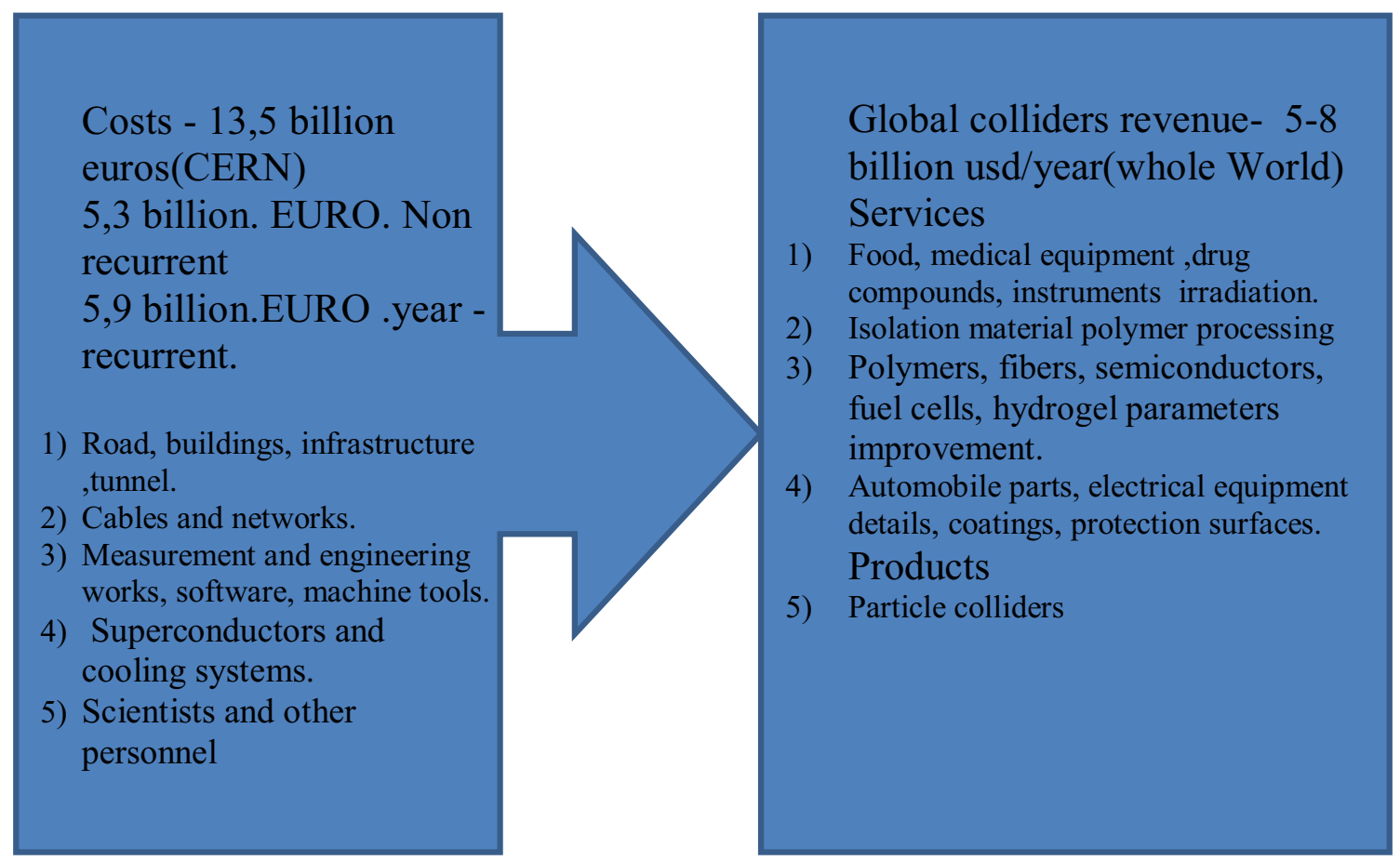

Fig. 8 Costs and potential comparison for collider projects on CERN example

have thousands and millions of unpredictable collisions with other electrons proving unpredictable combinations of possibly chemically toxic molecule appearance. In addition it was shown that prediction of all this combinations is barely possible even with the most powerful computational systems in chemistry and biotechnology [31]. ${ }^{4}$ То есть не возможно предугадать появление опасных токсичных веществ и радикалов.

Figure down aggregates S\&T expenditures on collider and particle physics project on the CERN example with global economic output of collider applications. It is evident from the figure that such projects are mainly expendable rather than profitable. Their cost dimensions and variables are large while applications size and path is pretty narrow (Fig. 8).

Colliders market assessment faces same obstacles as high level of cross technological dependence of accelerators and conjugated technologies. Though all general evaluations fluctuate round same value in 3 billion USD. ${ }^{5}$ for colliders sold and 50 billion USD. ${ }^{6}$ for colliders sild with services and subordinate products. Though some authors

\footnotetext{
${ }^{4}$ Sevilla et al. [31].

5 http://accelconf.web.cern.ch/accelconf/ipac2013/talks/weib2 01_talk.pdf.

${ }^{6}$ https://www.cockcroft.ac.uk/wp-content/uploads/2016/07/Appli cations_1.pdf.
}

\section{SN Applied Sciences

make evaluation for goods and services for collider market comparable to all global market similar to those with USA and Japan only [3]. But this can be the result of market frames variations from one study to another as this author include the aggregated cost of irradiated products. In addition it should be stressed that some of the markets like ion beam implantation has quite unique properties creating strong barriers. Ion beam processing of polymers for crosslinking, grafting, solubility increasing and weight reduction has very strong competitive pressure from conventional chemical technologies. So the only proven markets for colliders as well as Super Tau Charm Fabric in Novosibirsk and NICA project in Moscow are food and medical devices irradiation (Fig. 9).

Despite a number of applications collider applications are very specific and narrow. While improving some characteristics they this technology is dependent from vertically and horizontally integrated technologies like machine tools and other equipment. Another disadvantage of such market evaluated with upper level of 5 billion USD. is very rapid saturation due to long life cycle of colliders. lon beam food processing services are country dependent as they all require various certifications and linked to local production chains. 
Fig. 9 Number of colliders in each collider application segment

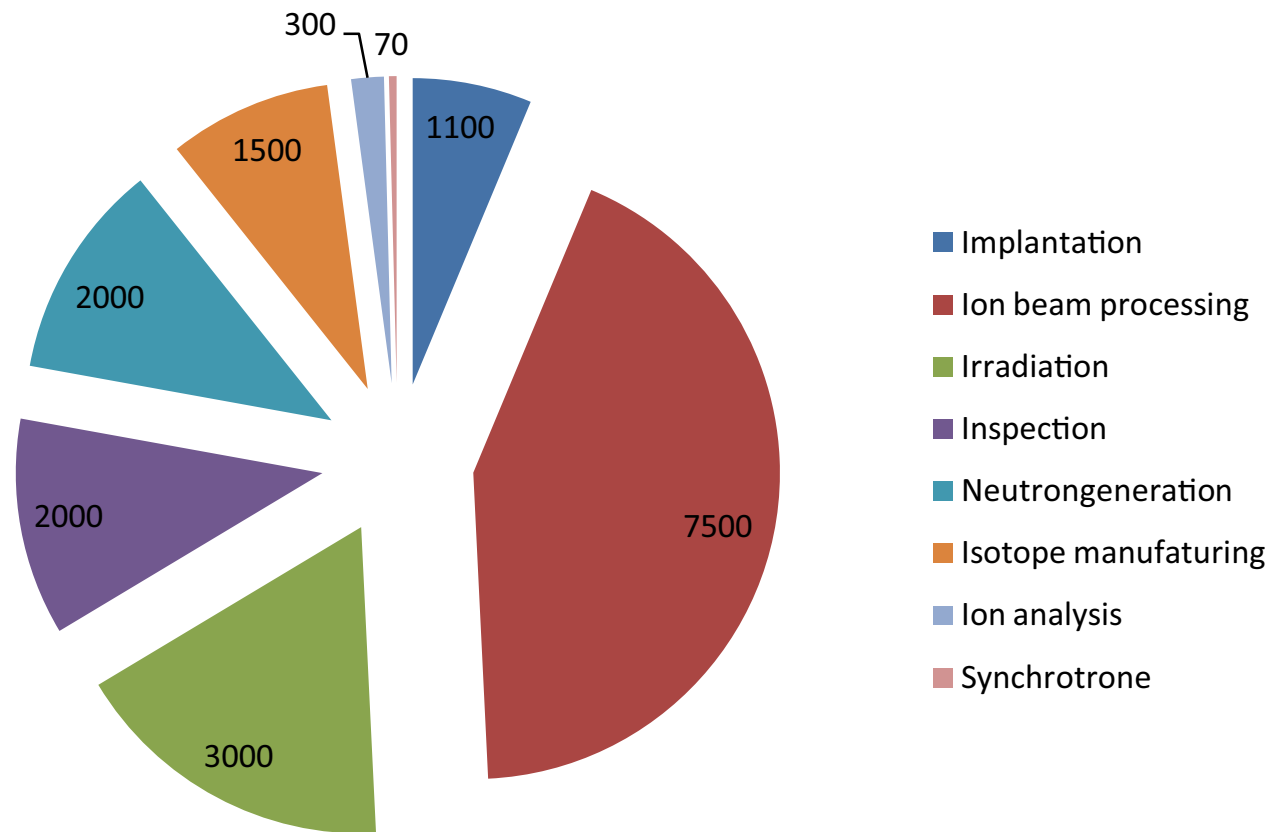

\section{Conclusion}

Recently Elementary Particle Physics with subordinate collider technologies is integrated in economic system but this integration is very specialized and incapacious. Its main part-nuclear physics stemming from discoveries from the first half of twentieth century implemented itself in large number of technological directions though its economic share is not so large as main technologies lik photonics or IT. And its part that is already found itself on the market is not expanding due to low number of possible variations and integration with other technologies as neural map showed.

There is a general lack of market size caused by high competition. There are 71 centers proving irradiation services in the world creating strong competition in both research areas and finial market products and services. Colliders find their applications though they face serious pressure from competitive technologies and sometimes loosing in various properties like penetrative depth, radiation safety, scale, toxicity but they stay as one of the prosperous frontiers for new horizons in the far future.

\section{Compliance with ethical standards}

Conflict of interest The authors declare that they have no conflict of interest.

\section{Appendix: RNPV model}

Formula: $r N P V=R_{0}\left(P_{n p v}-\sum_{i=0}^{n} \frac{C_{\text {inpv }}}{\text { Rinpv }}\right)$.

Revenue per collider 100,000 usd.

Number of units sold per year $=2000$.

Number of employees engaged $=1000$.

Duration of project 8 years.

$R \& D$ and engineering $5,000,000$ usd.

See the Tables 3 and 4. 


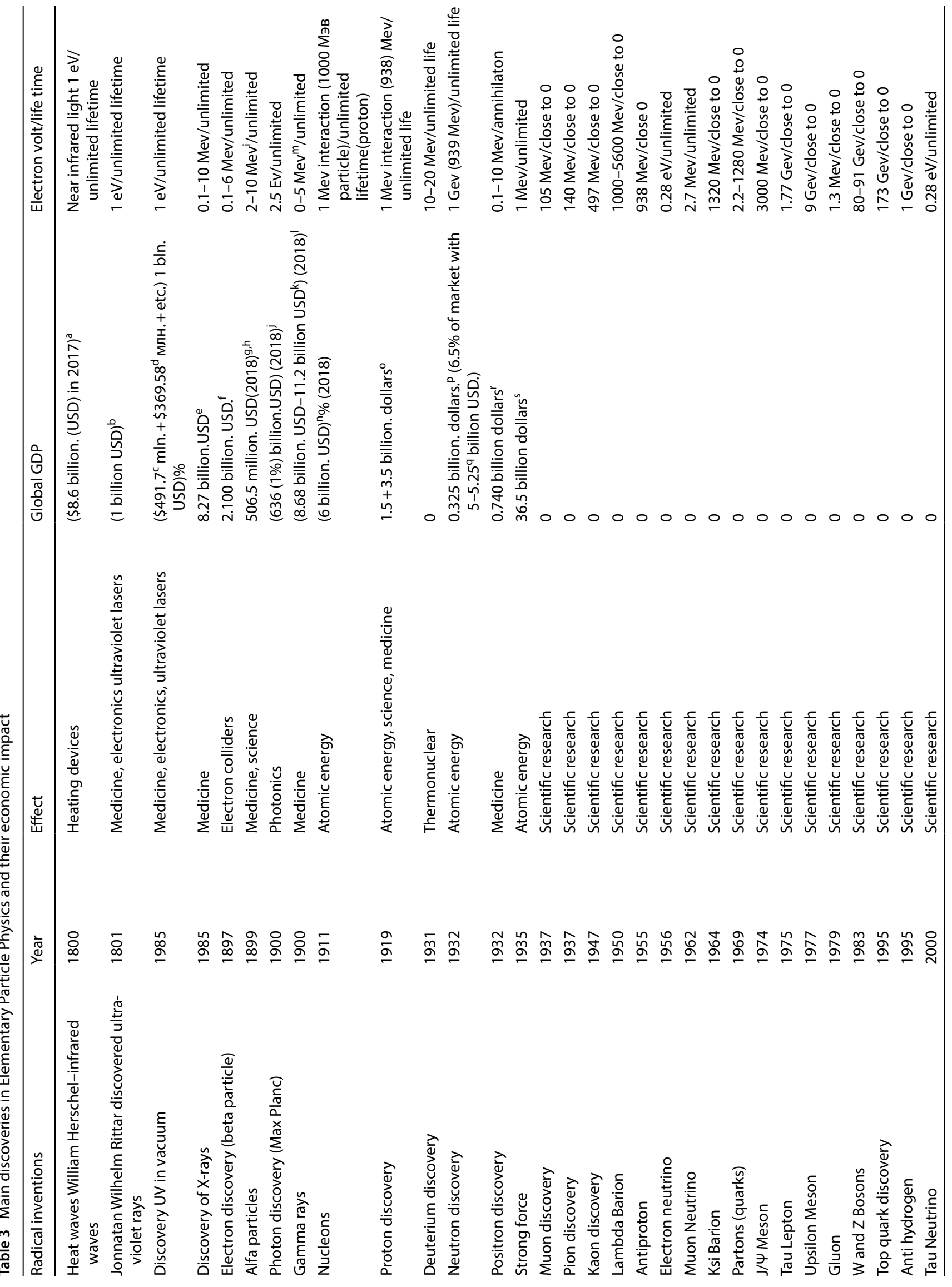


SN Applied Sciences (2020) 2:419 | https://doi.org/10.1007/s42452-020-2164-y

Research Article

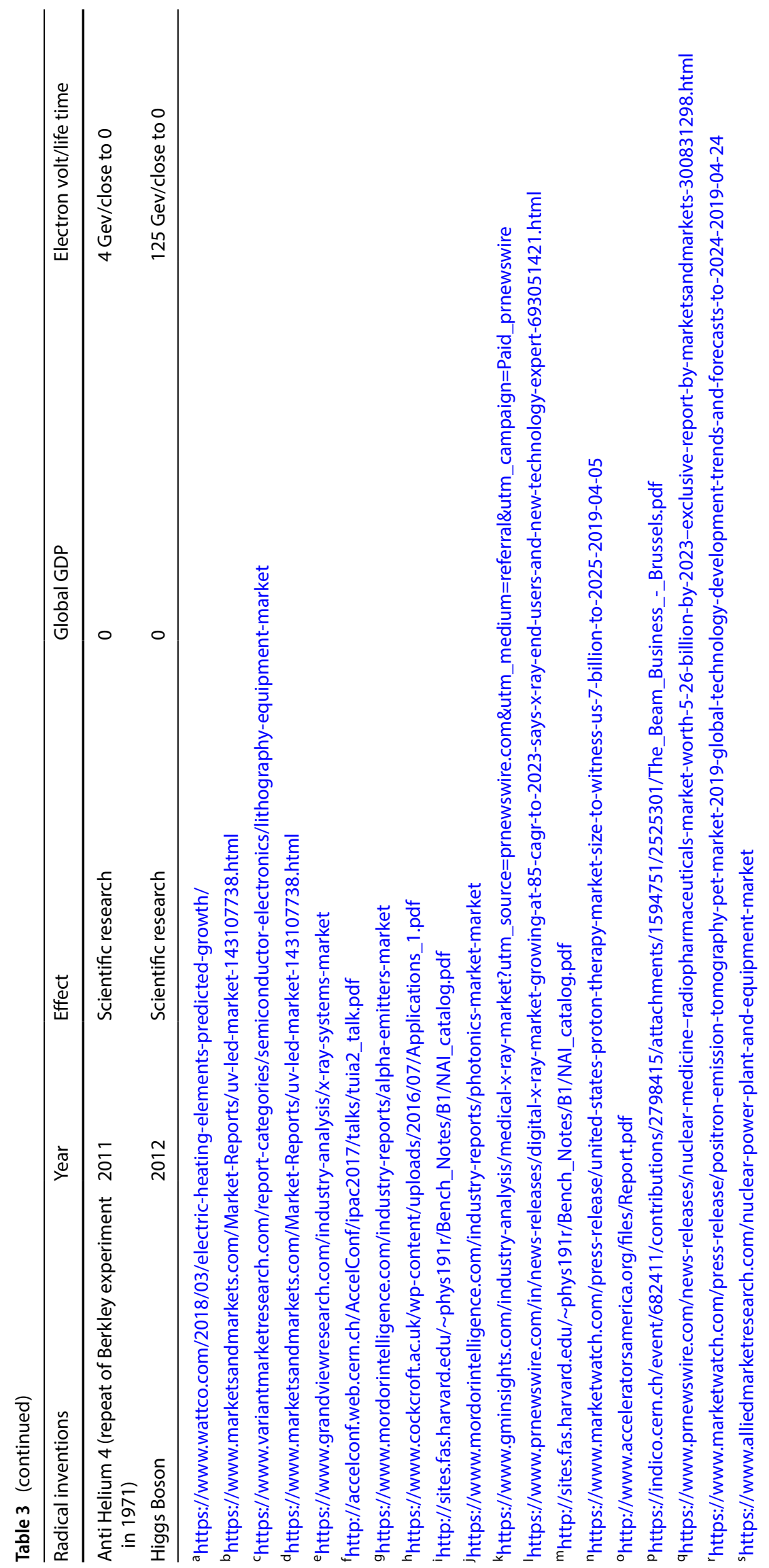

SN Applied Sciences

a SPRINGER NATURE journal 


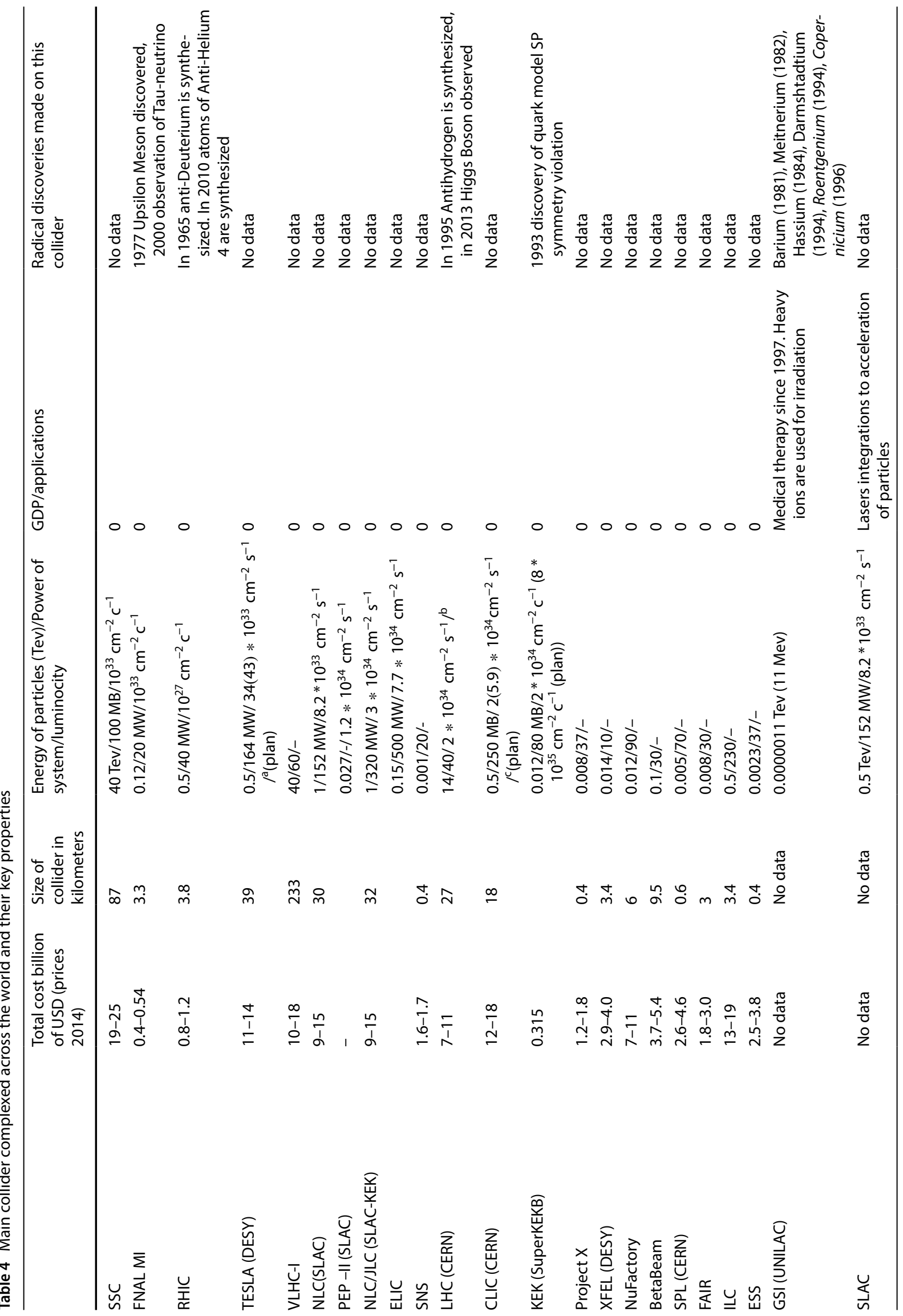

SN Applied Sciences

A SPRINGER NATURE journal 


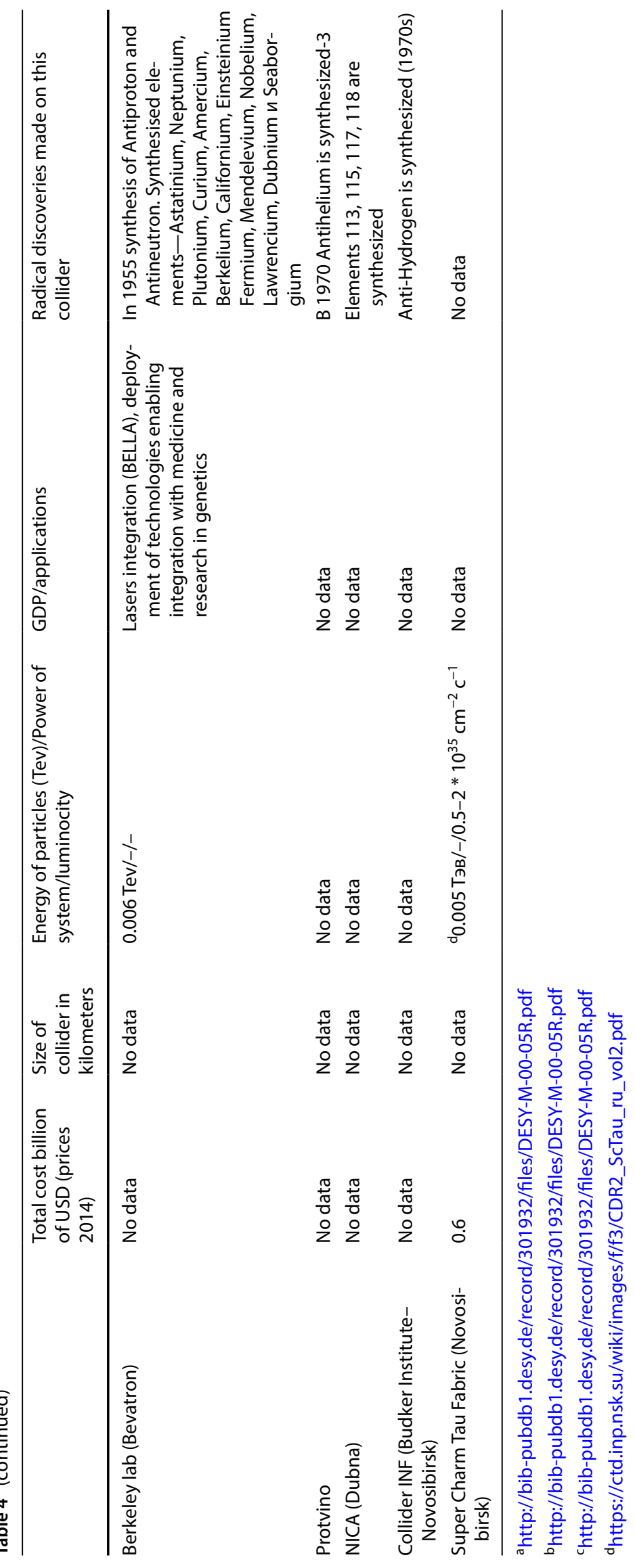




\section{References}

1. Shiltsev V (2014) A phenomenological cost model for high energy particle accelerators. J Instrum 9(07):T07002

2. Florio M, Forte S, Sirtori E (2015) Cost-benefit analysis of the large hadron collider to 2025 and beyond. ArXiv preprint arXiv :1507.05638

3. Tagawa S, Kashiwagi M, Kamada T, Sekiguchi M, Hosobuchi K, Tominaga $\mathrm{H}$, Makuuchi K (2002) Economic scale of utilization of radiation (I): industry comparison between Japan and the USA. J Nucl Sci Technol 39(9):1002-1007

4. Kohonen T (2013) Essentials of the self-organizing map. Neural Netw 37:52-65

5. Brereton $\mathrm{R}$ (2012) Self organising maps for visualising and modelling. Chem Cent J 6(2):1-15. https://doi. org/10.1186/1752-153x-6-s2-s1

6. Petersen KJ, Handfield RB, Ragatz GL (2005) Supplier integration into new product development: coordinating product, process and supply chain design. J Oper Manag 23(3-4):371-388

7. Breschi S, Lissoni F, Malerba F (2003) Knowledge-relatedness in firm technological diversification. Res Policy 32(1):69-87

8. Bloom N, Schankerman M, Van Reenen J (2013) Identifying technology spillovers and product market rivalry. Econometrica 81(4):1347-1393

9. Jaffe $A B(1986)$ Technological opportunity and spillovers of R\&D: evidence from firms' patents, profits, and market value. Am Econ Rev 76(5):984-1001

10. Nooteboom B, Van Haverbeke W, Duysters G, Gilsing V, Van den Oord A (2007) Optimal cognitive distance and absorptive capacity. Res Policy 36(7):1016-1034

11. Gilsing V, Nooteboom B, Vanhaverbeke W, Duysters G, van den Oord A (2008) Network embeddedness and the exploration of novel technologies: technological distance, betweenness centrality and density. Res Policy 37(10):1717-1731

12. Bar T, Leiponen A (2012) A measure of technological distance. Econ Lett 116(3):457-459

13. Nesta L, Saviotti P (2005) Coherence of the knowledge base and the firm's innovative performance: evidence from the US pharmaceutical industry. J Ind Econom 53(1):123-142

14. Carlsson G, Memoli F (2010) Characterization, stability and convergence of hierarchical clustering methods. J Mach Learn Res 11:1425-1470

15. Uršič R (2010) Present status and future outlook of the accelerator industry in Europe. In: Conf Proc (vol 100523, no IPAC-2010WEIRA04, p WEIRA04)

16. Meissner J et al (2000) X-ray treatment at $5 \mathrm{MeV}$ and above. Radiat Phys Chem 57(3-6):647-651

17. Peralta EA, Soong $K$, England RJ, Colby ER, Wu Z, Montazeri $B$, McGuinness C, McNeur J, Leedle KJ, Walz D, Sozer EB, Cowan B,
Schwartz B, Travish G, Byer RL (2013) Demonstration of electron acceleration in a laser-driven dielectric microstructure. Nature 503:91-94

18. Vranic M, Klimo O, Korn G, Weber S (2018) Multi-GeV electronpositron beam generation from laser-electron scattering. Sci Rep 8:1-11

19. Burke DL, Field RC, Horton-Smith G, Spencer JE, Walz D, Berridge SC, McDonald KT (1997) Positron production in multiphoton light-by-light scattering. Phys Rev Lett 79(9):1626

20. Arns R (2001) Detecting the neutrino. Phys Perspect 3(3):314-334

21. Tang A (2008) Neutrino counter nuclear weapon. ArXiv preprint arXiv:0805.3991

22. Haldrup K, Levi G, Biasin E, Vester P, Laursen MG, Beyer F et al (2019) Ultrafast X-ray scattering measurements of coherent structural dynamics on the ground-state potential energy surface of a diplatinum molecule. Phys Rev Lett 122(6):063001

23. Jenkins JH, Fischbach E (2009) Perturbation of nuclear decay rates during the solar flare of 2006 December 13. Astropart Phys 31:407-411

24. Jenkins JH, Fischbach E, Buncher JB, Gruenwald JT, Krause DE, Mattes JJ (2009) Evidence of correlations between nuclear decay rates and Earth-Sun distance. Astropart Phys 32(1):42-46

25. Stefanovic $P$, Kurasova $O$ (2011) Visual analysis of self-organizing maps. Nonlinear Anal Modell Control 16(4):488-504

26. Palmer RB (1987) Collider scaling and cost estimation. In: New techniques for future accelerators. Springer, Boston, MA, pp 105-120

27. Florio M (2019) Investing in science: social cost-benefit analysis of research infrastructures. MIT Press, Cambridge

28. Atkinson G, Mourato S (2008) Environmental cost-benefit analysis. Ann Rev Environ Res 33:317-344

29. Pearce DW, Atkinson G, Mourato S (2006) Cost-benefit analysis and the environment: recent developments. OECD Publishing, Paris

30. Sudprasert W, Navasumrit P, Ruchirawat M (2006) Effects of lowdose gamma radiation on DNA damage, chromosomal aberration and expression of repair genes in human blood cells. Int $J$ Hyg Environ Health 209(6):503-511

31. Sevilla MD, Becker D, Kumar A, Adhikary A (2016) Gamma and ion-beam irradiation of DNA: free radical mechanisms, electron effects, and radiation chemical track structure. Radiat Phys Chem 128:60-74. https://doi.org/10.1016/j.radphysche m.2016.04.022

Publisher's Note Springer Nature remains neutral with regard to jurisdictional claims in published maps and institutional affiliations. 